\title{
The International Community and the Environment*
}

\author{
by \\ Maurice F. Strong \\ Chairman of the Bureau, I.U.C.N., 1110 Morges, Switzerland, and Chairman of Petro-Canada, \\ P.O. Box 2844, Calgary, Alberta, Canada; formerly Secretary-General of the United Nations Conference on the Human Environment \\ and subsequently Executive Director of the United Nations Environment Programme.
}

\section{INTRODUCTION}

It is a signal honour to have been asked to deliver this lecture to commemorate the outstanding contributions of Jean Baer and Julian Huxley to the cause of conservation. Both of these great men devoted their genius as scientists to helping us to broaden our perceptions of the human condition and their talents as leaders to establishing the institutions needed to safeguard and to improve the conditions of life on this planet. No two individuals did more to establish the foundations on which environmental conservation can now be seen and dealt with as a critical global issue.

It is therefore perhaps fitting that I use this occasion to assess the progress which has been made in the evolution of conservation as a major global issue and point up what I see as the major challenges that now confront us - particularly those of us who are committed to carrying on the work which Jean Baer and Julian Huxley so notably made their own.

I speak as a layman and an internationalist, but one who has been privileged in recent years to be directly involved in the processes of dealing with environmental conservation at the world level. I am neither scientist nor politician. But my work has been on the interface between science and public affairs, and in it I have been involved closely with both-with the result that I have formed a deep appreciation of the importance of both. To me it is clear that any solution to the

* Substance of the first Baer-Huxley Memorial Lecture, delivered at the Hotel Loftleidir, Reykjavik, Iceland, on the evening of Wednesday 8 June 1977, after the mid-conference excursion during the Second International Conference on Environmental Future, with your Editor in the Chair. The Lecture was applauded with great enthusiasm which was followed by lively discussion that extended to midnight and involved, in addition to the Lecturer and Chairman (in the order of their first speaking), at least Ralph Glasser, Bent Juel-Jensen, Pierre Laconte, Arthur D. Hasler, Edward D. Goldberg, Peter B. Stone, E. Barton Worthington, Thomas F. Malone, Nicholas G. L. Guppy, Gary L. Widman, Edward Goldsmith, Elizabeth Dodson Gray, Fatehsinghrao Gaekwad (Maharaja of Baroda), Perez M. Olindo, Michael G. Royston, Richard G. Miller, Errol Cunningham, and Torgny Schütt.-Ed. present human dilemma requires the closest and most sensitive and positive interaction between the practitioners of science and those of public affairs.

First let me say a few words about my own use of the terms 'conservation' and 'environment'. I will use the former in its traditional sense as denoting the preservation and care of Nature and natural resources and also their economical use. There is still no generally accepted definition of environment. In the preparatory committee for the Stockholm Conference, long discussions took place in an effort to agree on a satisfactory definition, and the effort finally had to be abandoned. When I use the term 'environment', I use it as the umbrella term embracing the whole spectrum of issues which derive from Man's interactions with the natural environment and the effect of these interactions on both Man and Nature.

Although 'conservation' and 'environment' are far from being synonymous, it was the conservationists who pioneered the modern environmental movement and laid its foundations. Conservationists continue to provide the core of the leadership of concern for the environment; indeed their voices are heard and respected as never before. Thanks to the pioneering work of men like Julian Huxley and Jean Baer, the protection and improvement of the environment have become global concerns.

\section{STOCKHOLM: BEFORE AND AFTER}

The United Nations Conference on the Human Environment, held in Stockholm in June 1972-just 5 years ago-moved the environmental issue into the centre of the world political arena, and established it as an important item on the agenda of governments throughout the world. The concern for environment which led to the convening of the Stockholm Conference came almost exclusively from the industrialized countries. It was rooted in the growing evidences that the processes of urbanization and industrialization, which had produced such benefits for their societies, 
were also producing unexpected costs-pollution of air and water, mounting threats to the survival of wildlife, desecration of coastal, forest, and wilderness, areas, and deterioration of the quality of urban life.

These were all issues of small interest to the developing countries. They insisted that, if they were going to take 'Stockholm' seriously, it had somehow to be made relevant to their primary preoccupation with development. They made it clear that they thought under-development and poverty constituted the most acute and immediate threat to the environment of their peoples. Thus, the agenda of the Conference, and the very concept of environment, were broadenedquite rightly-to embrace such issues as loss of productive soil and the march of the deserts, the management of tropical ecosystems, provision of pure water for human use, and the problems of human settlements. Thus the less-developed countries forced a clear recognition of the relationship between environment and development-of the truth that it is through the process of development that the environment is affected, either positively or negatively, and that it is through the planning and management of the development process that we must deal with the care and protection of the environment.

This broadened approach to the environment became the basis for participation of developing countries in the Stockholm Conference and for the rapid evolution of their interest in environment. It also had a decisive effect on the shaping of the recommendations of the Stockholm Conference and on the content and direction of the subsequent United Nations Environment Programme. The use, by the developing countries, of their majority vote in the United Nations General Assembly, to have the headquarters of the United Nations Environment Programme established in Nairobi, Kenya, provided dramatic evidence of the influence of the developing countries in shaping this new international organization devoted to an issue in which they initially had little interest.

The strong role of the developing countries at Stockholm and in the United Nations Environment Programme has been accompanied by a degree of interest and activity at the national level which is nothing short of remarkable in the light of the attitudes of these countries prior to Stockholm. Virtually all of them today have established at least the beginnings of national policies, legislation, and governmental organizations, to deal with environmental issues. At the international level, in addition to the United Nations Environment Programme, which grew directly out of the Stockholm Conference, UNESCO's Man and the Biosphere Programme, the International Union for Conservation of Nature and Natural Resources, the World Wildlife Fund, the Foundation for Environmental Conservation, and the
International Institute for Environment and Development, all of which (or their prototypes) preceded Stockholm, have assumed increasingly important roles.

Environment-related activities of most concerned international organizations, including such major UN agencies as the World Bank, FAO, WHO and UNDP, UNESCO and WMO, have grown significantly. United Nations conferences on Food, Habitat, Water, Desertification, and the Law of the Sea, have focused or are focusing particular attention on a series of special issues related to the environment. The scientific community has become increasingly active through such organizations as the International Council of Scientific Unions and its SCOPE Committee, the International Institute for Applied Systems Analysis, and the International Federation of Institutes of Advanced Study. A number of new awards have been created to recognize achievement in the field of environment. Here I would like to pay special tribute to Professor Polunin and those who have worked closely with him to enable these International Conferences on Environmental Future to make an especially significant and useful contribution to the international environmental movement.

The growth of institutions, on both national and international levels, and the proliferation of activities since Stockholm, testify to the fact that environment has arrived as an issue. In the last 10 years the amount of progress that has been made in creating awareness and concern can be a source of very considerable gratification-particularly for those whose pioneering work provided the foundations on which this progress has been made. Here we should recall such influential journals as Biological Conservation and particularly Environmental Conservation, both established by Nicholas Polunin. But we must now ask ourselves hard questions about where we currently are and where we are going.

\section{ENVIRONMENTAL AWARENESS AND PROTECTION}

Granted that environmental awareness has been extended to virtually every corner of the globe, we must ask how deeply it has penetrated and the extent to which it is actually influencing the behaviour of people and the actions of governments and institutions. We must examine soberly what we are actually doing to change the habits and the practices that have produced the environmental deterioration and risks of which we have become so aware. We must try to see where we are headed and what we must now do to influence the shape and direction of our future.

Against this set of questions I have to say that all the progress we have made represents only a beginning: the actions we have taken so far have been the easy ones. 
It is true that there have been some impressive examples of how specific environmental problems can be dealt with by concerted and enlightened action. For example, there have been some very considerable advances in some places in the forward planning of resource use. In Malaysia, where much land still remains under tropical rain-forest, careful advance planning of land capability for mining, agricultural development, forestry, and other uses, has ensured that forest is not opened up before its use is finally decided on. Moreover, careful attention is being given to maintaining chosen areas in a natural state as national parks and reservoirs of the rich genetic material of the tropical rain-forest. In the United Kingdom, after a head-on collision between conservationists and proposals for a new reservoir ('the Teesdale affair'), regular advance consultation took place between those planning for the development of water resources and those concerned with the conservation of Nature. As a result of this consultation long before plans become public, there has been no further direct conflict since 1965. Full account has also been taken, in planning alternative approaches to largescale water developments-such as the Wash and Morecambe Bay barrages-, of the ecological effects and the implications for conservation.

Enormous progress has been made in Iran to demonstrate how rapidly and effectively natural ecosystems can recover with protection. Results have included great increases in the numbers of wild sheep, ibex, and gazelles, and there has been widespread recovery of vegetation even in very arid regions. The next stage is the difficult one of controlling use of these ranges, which should be capable of cropping at a much higher level than before they were protected. If this can be accomplished, it will provide a clear demonstration of the speed and economy of natural recovery. The success of conservation programmes, mounted to reverse the drastic decline in the populations of Vicuna and Polar Bears, shows clearly that timely and concerted action can ensure the survival of other endangered species of animals.

These examples are encouraging in that they demonstrate that we do have the capacity to deal successfully with many of the specific environmental problems which are now facing us. The technological and managerial capabilities of industrial Man, and the recuperative powers of Nature, can be powerful allies in remedying environmental ills. Indeed, I would go further: Man has the capacity to deal with all the major environmental problems which now confront him. Eco-disaster is not inevitable; it is within our power to prevent it. Yet, I cannot help but feel that technological Man is proceeding along a course that can only lead to disaster. Consider the evidence.

\section{OMINOUS TENDENCIES}

While we have shown the ability to deal with individual environmental ills, curing them in many ways, this is like treating a sore on the body which is caused by an infection that has spread throughout the body. It may bring some temporary relief; but unless the underlying ailment is dealt with, the body cannot be restored to good health.

Consider some of the Earth's oldest and richest ecosystems, the tropical rain-forests. About 80 per cent of the world's tropical rain-forests have disappeared already, and the remainder is being felled and burned at the rate of 11 million hectares a year-more than 30,000 hectares a day, or 20 hectares a minute. In Africa more than half, and in India, Sri Lanka, and Burma, almost two-thirds, of the original rain-forest cover is now gone. The richest lowland areas are the most vulnerable: the plant communities of south-east Asia are among the most species-rich in the world, but those of the Philippines and Malaysia are expected to have vanished completely within the coming decade.

This tragic waste is proceeding unimpeded by all the efforts of conservationists. Even in areas where they have used their most eminent names to persuade and cajole the local decision-makers and wielders of power, conservationists have as yet made no decisive difference. In the Philippines, for example, the late Charles Lindbergh and Tom Harrisson worked long, hard-and in the end successfully-to persuade the Government to establish the Mt Apo National Park. Mt Apo Park protects both one of the finest Dipterocarp forests in the Philippines (and hence in the world) and the only home of the endangered Monkey-eating Eagle. Yet today four-fifths of the Park has been designated for logging and settlement.

Destruction of the world's tropical forests would constitute a loss more critical to the human future than the depletion of its oil and gas reserves. The IUCN and the World Wildlife Fund have mounted a large-scale programme aimed at reversing this dangerous trend before it is too late.

What may be the final session of the Law of the Sea Conference is now in progress. Its results will determine how some 70 per cent of the Earth's surface-the sea-bed, the sea, and its living resources-will be cared for, exploited, and managed. It may well have more profound effect on the future security and well-being of the human species than any other issue now before the world community. Yet most people seem scarcely interested or aware of the issues at stake. Few realize the danger that the narrow, short-term interest of those primarily concerned with exploiting ocean resources will override the larger interest of all mankind in the careful management of the oceans and conservation of their resources. But this is preci- 
sely what now seems likely to happen-unless there is a dramatic last-minute change in the attitudes of the governments negotiating these issues.

The oceans and salt seas constitute the world's biggest wilderness, where hunting is a multi-million dollar activity involving some of the most sophisticated technology, where the long-established terrestrial practice of domesticating animals and plants has scarcely a toehold, where conservation and environmental management have most to offer-and have failed dismally. A growing number of fish stocks are being depleted: for example, north-east Atlantic hake and herring, north-west Atlantic haddock, north-west Pacific salmon, Mauritanian-Senegalese hake, easterncentral Atlantic squids, and south-east Atlantic pilchards. In addition, some 12 species of whales, dolphins, and porpoises, 9 species of seals, all Dugongs and Manatees, all coastal crocodiles, all sea-turtles, and 30 species of sea- and shore-birds, are more or less threatened with extinction.

No attempt is being made to relate the effects of harvesting different species on one another, or the impact of harvesting with other impacts on the sea (such as pollution and incidental take). So the assumed potential harvest of a given stock may often be put too high. Similarly, decisions on other uses of the sea (for example, on whether to mine or dump or drill for oil) are made in ignorance of the likely impact on fish, marine mammals, or the populations of other organisms on which they feed.

Until the seas are managed for what they aredynamic systems of biological and physical processes extending widely over time and space-they will continue to be managed badly. Management authorities with jurisdiction and interests confined to a few species or to a single nation are no longer enough: regional management authorities, capable of looking after whole ecological areas, are now essential. The recent convention on the Mediterranean is a promising step in this direction.

Our technological societies have also been shamefully irresponsible and insensitive in their response to the fate of the many indigenous peoples whose societies are being relentlessly decimated in the name of growth and progress. In both industrialized and developing countries, these peoples, who desire to live their traditional lives as nomads or hunters and gatherers, today constitute endangered 'species'. Yet they are the repositories of most of the evolutionary experience of the human family, much of which we must now re-discover and learn to apply to the shaping of a viable future. The destruction of these societies and the demise of these peoples would constitute a tragic and irreparable loss to the entire human community.
NEED TO CONTROL GROWTH

All of these things are occurring as a result of the increasing demands which the human population is placing on the resources of the biosphere. And Man's impacts on the environment result primarily from growth-growth in his numbers and growth in his appetite for material goods. Both must be brought under control.

Population growth in the industrialized societies has already levelled off; growth-rates in the lessdeveloped parts of the world continue to be high, but are also showing signs of subsiding. Nevertheless it seems possible that, by the early years of the next century, planet Earth will have to provide a home for double the present population-about four-fifths of them in the developing world-and this will create enormously increased pressures on natural resources and on the biosphere. Add to this the pressure that will result from the drive of the poor-who make up the major portion of the world's population - to improve their conditions of life, and the tremendous pressures already being placed on the system by the insatiable appetites of the rich minority, and you will see that something has clearly got to give way. In my view, that 'something' must be the appetites of the rich.

Population growth in the developing world must be stabilized, and this will happen either through voluntary methods of population control or the traumatic and tragic consequences of famine and disease or conflict.

Even the most hopeful assumptions about limitation of population growth in the developing countries lead to the conclusion that their claims on world resources will escalate sharply within the next three decades. For quite apart from their increasing numbers of mouths to be fed, they cannot be denied their right to achieve better conditions of life, and surely natural justice dictates that their claims be given first priorityfirstly, to assure the meeting of their basic needs for a life that is compatible with human dignity and wellbeing, and, secondly, for equal opportunity to share more fully in the benefits which our technological civilization now makes possible. This can only happen if the industrialized societies reduce the pressures which they are exerting on the biosphere and on natural resources.

There is little sign that the developed countries will reduce their demands voluntarily, for their existing commitment to continuous growth in gross national product is built right into the economic system by which modern industrialized societies function. It is based on the assumption that more is better-that the well-being of the societies can only be assured by continuous growth in the material sense. The expectations of consumers, the creation of employment, the 
incentives which motivate investors and managers, are all geared to this system in which material growth is the prime mover. And while there has been some serious questioning of this concept of growth during recent times, it remains the dominant theme on which modern societies operate.

To the people of the wealthy countries of the industrialized world, the suggestion that they should reduce their demands on global resources is immediately equated with calls for 'no-growth'-a state which none of them could conceive of as tolerable. Indeed, no-growth in the sense of the cessation of economic growth is not perceived as a viable alternative by any nation: it is equated with stagnation and resulting fears of unemployment, social unrest, and reduced standards of living.

It is this attitude towards growth-of human population and its production and therefore demands on the life-support system - that is at the heart of our present dilemma. This is the disease which has spread through the body of modern technological societies. It is this growth disease which has within it the potential for self-destruction of our society; and it is to the curing of this disease that we must direct ourselves if we are to deal fundamentally and effectively with the need to create a sustainable balance between Man and the natural environment.

\section{NEED FOR A NEW-GROWTH SOCIETY}

The challenge we now face is nothing less than that of creating a whole new approach to the growth of our society, to the goals of growth, to the processes of growth, and to the systems of incentives and penalties which determine our patterns of growth. Environment cannot be seen as an issue separate and distinct from growth - as an issue which can be dealt with simply by adding another element to our present growth practices. It is, after all, through the process of growth that we affect the environment, either positively or negatively, and environmental resources are both a contributor to and a product of the growth process. Thus preservation and improvement of the environment can only be ultimately effective if it is integrated into the complex of forces by which the growth of our societies is determined. Environmentalists must now take the lead in effecting the transition to a 'new-growth' society.

It is understandable that the early emphasis of environmentalists was on cleaning up some of the more obvious cases of environmental damage, on stopping development which threatened further damage, and on subjecting existing sources of pollution to controls or 'add on' technologies designed to minimize their environmental impacts. Now, some environmentalists have called for a halt to growth in our highly industrialized societies. At the other extreme, there has been a tendency to regard the costs of environmental protection or improvement as simply an extra or added cost-something that cuts into economic return, often to the point where we cannot afford it. We are told that protection of the environment is nice if you can afford it, but that when there is a conflict between economic and environmental factors, economic reality must prevail.

Yet what kind of economic reality is it that leaves out of the cost-benefit calculations on which economic decisions are based--the cost to society as a whole of maintaining the natural environmental capital of air, water, soil, and plant and animal life, on which human life and well-being depend? By what economic logic can the amounts required to preserve environmental values in a given economic situation be considered a 'cost', while the impairment of environmental capital that results from failure to make these expenditures is not seen as a cost? Surely, the reality lies in recognizing that in any activity which damages the environment, environmental costs cannot be avoided-that it is simply a question of how and when and by whom they are to be borne. Environmental realities cannot be avoided by ignoring them in the name of economic realities,

Economic growth has made possible some unprecedented benefits to society. But it has also enabled us to avoid facing up to certain basic truths which we must now confront. We now know that economic growth which depends on the running down and impairment of our natural environmental capital is neither sound nor sustainable. The bills must come in eventually. The growing damage, to our natural environmental capital, that is resulting from the same processes which produce the wealth of our societies, should make it clear to us that we cannot continue to grow as we have been doing in the past. A society which bases its growth on the degradation and using up of its natural environmental capital, will be no more viable than a business enterprise which does not provide an adequate depreciation and amortization account to maintain its capital and productive capacity. Yet, this is exactly what is happening today in varying degrees in almost all countries in both the industrialized and the developing world!

Individual examples of this wantonness are legion in the fouling of rivers and lakes, contamination of air, desecration of coastal areas, destruction of bird and other animal life, and deterioration of urban areas in the United States and other industrialized countries, while in the developing world we have massive destruction of forests, large-scale loss of productive soil through erosion, march of the deserts and other consequences of ecologically unsound land-use practices, and the appalling conditions of life in exploding urban areas through lack of adequate 
water supplies, waste disposal, and sanitation facilities. There is also the growing threat to rich and poor alike from such 'outer limit' risks as possible climatic change, damage to the ozone shield, contamination of human food-chains, pollution of the oceans, and overexploitation of their living resources.

Surely it must be clear that present growth-patterns and practices are self-destructive and cannot be sustained! Is no-growth then the only answer? Let me say with all the force I can muster that no-growth is NOT the answer. The real alternative to no-growth is new-growth-a new approach to growth, in both the more industrialized and the less-developed societies.

The new-growth approach must be based upon removal of the artificial and self-defeating conflict between ecology and economics, which is now built into our system of economic decision-making. We must make environmental concern and economics the allies they can and should be in evolving an approach to growth, the prime goal of which will be to produce a better quality of life for people. We must build into the system by which growth is generated and managed, wise measures that assure preservation of the resourceand environmental capital-base on which continued development depends.

In the more wealthy industrialized societies, this will mean a major transition to a less physical kind of growth that is relatively less demanding of energy and raw materials-one that is based to an increasing degree on the satisfaction of Man's intellectual, moral, and spiritual, needs and aspirations in such fields as culture, music, art, literature, and other forms of individual self-development and fulfilment. These, after all, are the areas in which Man achieves his highest levels of growth in human terms.

\section{CONSERVATION AND DEVELOPMENT}

Conservation must become a way of life, and incentives for it must be built into our economic system. In practical terms, this will mean a re-design of industrial systems to introduce super-systems in which the residues of one process become the raw materials of another. Technologies for recycling and re-use of materials and abatement of pollution must be integrated into such systems, not merely added on to them.

The conservation-development gap must be bridged. Conservationists must acknowledge that conservation is as much about people as it is about animals and plants, if not more so. It's not the presence of animals and plants that makes conservation necessary, but the presence of people. Therefore 'people experts' are practically as essential to conservation as are experts on Nature.
The proponents of development should recognize that conservation is a prerequisite for development, being the means whereby people can make the best use of the living resources on which they depend. But they will not be persuaded of this while so many conservationists appear to devote themselves to issues for their emotional appeal rather than attempting to concentrate on clearly-defined priorities that have been carefully arrived at through objective appraisal. Conservation is past the stage where being enthusiastic is enough, and should now seek to be as highly professional as are the promoters of reckless expansion.

On the global level, the 'new-growth' approach will require new dimensions of cooperation between industrialized and developing societies. It will require a re-vamping of the present international system of arrangements and institutions in such a manner as to enable them to support better and serve more effectively the interests and aspirations of the developing world. Interdependence, which is now a physical and environmental reality, must become a working reality in economic, social, and political, terms. This, in essence, is what the drive of the developing countries for a "New International Economic Order' is all about. The healthy functioning of our interdependent technological society requires the full participation and active cooperation of the twothirds of the Earth's people who live in the developing world, and this dictates that we heed their demands for a more just and equitable share of the benefits which this technological civilization makes possible.

Most new industrial capacity-particularly that which is resource- or labour-intensive-must be built in the less-developed parts of the world, and under conditions which enable developing countries to avoid many of the environmental and social costs that we have paid for our industrial development. The marriage of ecology and economics which I call 'ecodevelopment', would be designed to assure that the precious natural resources of soil, forests, water, and plant and animal life, in the less-developed countries are exploited in ways which make the best possible use of their own skills and labour, and harmonize with their own culture and value systems to produce maximum benefits for their people without destroying the resource-base on which sustained development depends. It means, too, assuring that they have full access to the latest technologies and support for the development of their own scientific and technological capabilities, so that technology will serve rather than determine their own growth-patterns.

The transition to a new-growth society which I am proposing has, perhaps, its best analogy in the human body. From the birth of a child to the time when it achieves physical maturity at the age of 18 or 19 , the principal emphasis is on physical growth. Indeed, 
healthy physical growth and continued physical health are essential pre-conditions to the growth of human personality in its social, cultural, intellectual, moral, and spiritual, dimensions; yet growth in these nonphysical aspects of human development has only nicely begun at the time that physical maturity is reached. The real growth is still to come. Our industrialized societies are very much like the physically mature human being. For us to continue to pursue purely physical kinds of growth would be as unhealthy and self-destructive to our societies as it would be for an adult person to pursue ways which simply added to his physical dimensions. And it would be just as wrong to say that societies must stop growing when they reach the stage of physical maturity as it would be to say that people stop growing when they stop growing physically.

The real growth of our societies in human terms is still ahead of us. But it demands that we change our ways and adapt to a more mature kind of growth that is less physically oriented and less demanding of resources and of the environment. On the other hand, developing countries are at a much earlier stage of growth in which they must continue to grow in physical terms if they are to meet the needs and aspirations of their people. But they too must emphasize the kinds of physical growth which are healthy and sustainable and provide expanding opportunities for selfexpression and fulfilment in human terms for their people.

Of course, acceptance of the need for the new-growth era will not automatically make it happen; indeed one is apt to wonder whether, in fact, it is a practical possibility? I believe that it is. But to practise it is a question both of the will and of the way, and I am convinced that the way must be easier to find than the will.

\section{NEEDED: CHANGED INCENTIVES AND PENALTIES}

The public-policy levers which governments can deploy today are capable of altering the system of incentives and penalties to which our economic life responds. We have clearly demonstrated this in fighting or preparing to fight wars. It is not the operation of the free market economy which produces the massive market for war materials. The market is created by an act of public policy by government, responding to the belief of their people that their security is at stake.

Today, the threat to our security through the physical and social imbalances generated by present growth-patterns, is to my mind as great as the threat of nuclear warfare. Indeed, it is even more difficult to deal with because it seems less immediate and less traumatic. The threat of a nuclear war may be averted right up to the moment when the button is pushed. But the threat of an ecodisaster can only be averted by foreseeing it far in advance and acting to prevent it. By the time it is upon us, it will be too late.

So, if we accept that the risk of ecodisaster is as great a threat to our security as that of nuclear warfare, we must use all the levers we can command to prevent it. And I am persuaded that, if we consider it important enough, we can prevent it. For the means are available to re-gear the system of incentives and penalties which motivate our economic life in such a manner as to make it profitable to carry out those activities which are environmentally sound and socially desirable, and unprofitable to do those things which impair environmental quality, destroy resources, and detract from desirable social goals. Far from being negative to the economy, a commitment to the 'new-growth' society would unleash new and dynamic economic forces and would stimulate creativity, innovation, and economic activity, across a broad front. If expenditures on war materials-which are inherently wasteful, whether or not they are used-can be a major stimulus to the economy, surely expenditures on building better and more liveable cities, improved cultural and educational facilities, and recreational areas and opportunities for meaningful leisure, can be just as stimulating to the economy, while at the same time adding positively to the real capital stock of our human societies.

It must be made economically attractive to conserve energy and materials, with corresponding penalties for activities which are destructive or wasteful of resources. Conservation must no longer be considered a fringe activity which is nice if you can afford it, but cannot be allowed to interfere with economic growth. It must become an essential element in all economic activity, and the whole process of economic decisionmaking must be designed around the need for a total commitment to conservation.

Let me say a special word about nature conservation as it is in danger of becoming the orphan of the environmental movement; for environmentalists concentrate on issues with more political clout, such as energy and nuclear power. It is worth remembering that environmental concern sprang from the efforts of the conservation movement, and that nature conservation remains the best organized and most cohesive part of a highly disparate collection of interests. The potential of nature conservation to wield political influence has been masked by the reluctance of many conservationists to confront directly those relevant issues with the greatest impact on ordinary people-fisheries being the outstanding example.

Governmental action must always be undergirded by a change in the attitudes, values, and expectations, of people. We should applaud and look up to those 
who adopt life-styles that are modest in terms of the amount of space which they monopolize or the amount of materials and energy which they consume; ostentatiously wasteful and indulgent living should become socially reprehensible. There should be an acute sensitivity to all activities which create risks of damage to our natural heritage, or impair the quality of life for others. People of industrialized societies in particular must again nourish their communal values and downgrade their competitive drives.

For clearly the transition to the 'new-growth' society implies some very profound changes in our present attitudes, expectations, and behaviour, and in some of our traditional notions of distinctions between private and public rights and responsibilities. Up to now, the human species has changed its ways only after having been chastized by bitter experience. Man's history has been based on repeated cycles of advance, tragedy inflicted by Nature or by war, collapse, and rebuilding on a higher level. Now that, for the first time in our history, we possess the means of total self-destruction, can we risk repeating these cycles? Even if we could, it is doubtful whether the wholly unprecedented scale and nature of the risks which we now face, would enable us to have another chance if we were to wait until environmental tragedy was imminent.

So while there is strong evidence that we can make the transition to a 'new-growth' society, there is a very real question as to whether we will do so. Our future really turns on whether we will have the enlightened moral and political will, and the sense of our own ultimate self-interest, to change our ways before it is too late.

It is in these terms that I see the challenge to our generation of environmentalists. Those who pioneered this movement have succeeded in placing the environmental issue firmly on the agenda of the world community. An increasingly concerned public, press, and media, have helped to keep it so, and there can be few major countries left in the world without a ministry or department of environment or whatever. The challenge which we now confront is to move from the fringes of debate and action to the very centre of the search for new approaches to growth. For it is in the need to reshape our attitudes towards growth, and to redirect the growth process itself, that the battle for the environment will be won or lost.

\section{Wolf-Wind}

A wolf-wind wails in the wilds of time, a red dawn colours the sky.

The grass turns brown, the beasts grow lean, the blossoms wither and die.

We earth-men know what the omens foretell, but power-men wrangle and vie.

Gather in, earth-men, trim down your flocks; Hark to the counsel of trees and of rocks.

Gather your blood-friends (Let chieftains glower!), For ours is the harvest of Terra's deep power.

Madison

Wisconsin 53704

U.S A. 